\title{
The formation of objects of the architectural environment with art perforated elements
}

\author{
Tatiana Karakova ${ }^{1,{ }^{*}}$, Sergey Kolesnikov ${ }^{1}$, Yana Radulova $^{1}$, and Julia Vorontsova $^{1}$ \\ ${ }^{1}$ Samara State Technical University, Molodogvardeyskaya str. 194, 443001 Samara, Russia
}

\begin{abstract}
The perforation principle of objects in environmental design is considered in this article, as well as the formation of objects of an architectural environment with the help of the perforation principle, and the interaction of perforated elements with shapes and luminous flux. This research improves the traditional knowledge of functional use of perforated surfaces (such as sun protection, soundproofing, health and safety requirements) in architectural and design objects. The research also systematizes and structures the methods of using them with the luminous flux in environmental design of objects in order to find some new forms and compositional effects.
\end{abstract}

\section{Introduction}

In architecture and design, perforation has many functions; one of them is the search of a new formation. As a method, perforation is used regardless of the scale of the designed object no matter whether it's a theatre building or a private interior design item. Perforation helps to reach diverse spatial effects and optical illusions. This method is also able to dramatically change the visual perception of an object and space. Originally, the perforation method was very narrowly applied; its usage was limited only by functional needs (perforated metal sheets were used in industry and agriculture) [1]. Later, perforation has become relevant in artistic and decorative ways. It's now widely used in environmental and interior design, household items and art objects. Nowadays, the emergence of modern materials gives designers and architects an opportunity to apply the perforation method to get new shapes and images. Technological development allowed making openings and holes of various shapes and sizes in metal, glass, concrete, wood. Consequently, it broadens functional tasks of using any perforated surface (noise absorption, sun protecting etc.) The principle is transferred on the facades of buildings and elements of interior. It also changes the compositional structure of a designed object. It also changes the shape, interacts with the luminous flux and gives an opportunity to feel and understand the space and objects differently. The effect of a perforated plane (facades, partitions etc.) can be acquired not only by means of the familiar perforation method (making holes in different materials), but also by iron art casting and mutual imposing of different surface. So, the "illusion of a perforation" is created. So far, the perforation principal is a versatile method, that possesses a wide range of functions, and it's used in all spheres of modern design. The

\footnotetext{
*Corresponding author: t.karakowa@mail.ru
} 
origin of the term "perforation" comes from the English verb "to perforate" which means "to make holes". The final result of such an action would be the acquirement of a significant number of properly placed holes and openings on a sheet or any other material $[2]$.

\section{Theory}

The foundation of different factories that specialized in producing metal sheets established the development and wide spreading of perforated surfaces at the end of the 19th century. In 1885, one of the first factories to start was "The factory of metal sheets and perforated tins" that belonged to the Belgian industrialist Chopard. Items made of metals and perforated sheets were used for sifting and calibrating grains as well as for dressmaking and in coal industry. Besides, the factory produced decorative perforated sheets. At the beginning of the 20th century, the development history of the perforated surfaces develops on a large scale. Perforated metal sheets are widely used in industrial and agricultural producing during this period. New tasks that arose for industrialists and architects predetermined the necessity of making perforated surfaces of wood, plastic, concrete, glass, composite materials and stone. Undoubtedly, these tasks required that the manufacturing technology had to become more complicated. The retrospective analysis of the perforated surfaces manufacturing and its recommencing has shown, that the basic stages of this development are very specific:

1. The 1885-1998 period - Functionalism prevails in manufacturing and using perforated surfaces in the architectural and design practice.

2. The 1998-2010 period - apart from functional using, perforated surfaces are widely implemented in the architectural space and interior design practice.

3. The period from 2010 to the present days should be considered as an architectural and design boom in using perforated surfaces for the search of new formation and creation of unbelievable visual effects.

The recommencing of the perforated surfaces manufacturing process began with the technological development of metal processing and cutting, and getting holes in metal sheets. Most part of technological procedures was registered before 2000. Here is the chronological consequence of recommencing of the metal processing:

- gas cutting - the technology was developed in 1840;

- waterjet cutting - the technology was developed in 1947;

- plasma cutting - the technology was developed in 1950;

- laser cutting - the technology was developed in 1971;

- waterjet cutting for getting holes in glass and concrete - the technology was developed in 1980 .

Among the newest technologies, there is also using of computer technologies and a 3D printer using for getting new perforated surfaces. This can also include creating perforation with the help of hot casting, vacuum molding, drilling with CNC (computer numerical control) assistance. Modern laser machines (laser cutters) and technological opportunities allow producing a huge amount of different kinds of grooves and orifices according to given technical drawings with high accuracy and quality. Materials can be different, for example wood, plastic, rubber, polyethylene, plywood, leather, cardboard, fabric etc. Laser processing is the most perspective and competitive technology nowadays [4].

Let's consider the content factor of getting perforation using modern technologies in different building and finishing materials:

1. Laser cutting implies the technology of cutting materials with lasers of high power. An automatically controlled laser beam can process any material with any thermophysical properties. It also minimizes a mechanical impact. The laser cutter performs 
a high degree of accuracy and can make most elaborate outlines. Laser cutting prevents the surfaces from mechanical contact with easily deformed or fragile materials, because it burns the holes and openings. It can process the materials of solid alloy metals and sheet steel; it gives an opportunity to cut materials under the condition of releasing large quantities of sheets as well.

To perform laser cutting designers create a template in graphics editor. Different graphic editors create a working file for laser cutters. The sheets of materials can be the following:

- steel sheets from $0.2 \mathrm{~mm}$ to $20 \mathrm{~mm}$ thick;

- stainless steel sheets from $0.2 \mathrm{~mm}$ to $30 \mathrm{~mm}$ thick;

- aluminum alloy sheets from $0.2 \mathrm{~mm}$ to $20 \mathrm{~mm}$ thick;

- brass sheets from $0.2 \mathrm{~mm}$ to $12 \mathrm{~mm}$ thick;

- copper sheets from $0.2 \mathrm{~mm}$ to $15 \mathrm{~mm}$ thick and many others.

They use various laser cutters for processing different materials [4].

2 . The waterjet cutting is a special way of processing sheet materials with water under high pressure that creates the effect of water erosion [4].

This technology has a lot of benefits, such as the absence of thermal stresses on materials, while the temperature in the cutting zone is about $60-90{ }^{\circ} \mathrm{C}$; minimal losses of materials; diversity of processed materials and their thicknesses (from 150 to $300 \mathrm{~mm}$ and more); high efficiency of cutting sheet materials; the absence of burnouts and melting of materials during the processing; a multilayer cutting of sheet materials; fire and explosive safety of processing; eco-friendly processing; a high quality of cutting and perforating.

3. Casting is a technological process of producing blanks by filling casting forms with liquid materials (metal, alloy, plastic etc.) and its further solidification [4]. The diversity of casting forms is defined by the specificity of the technological process. It can be manual or machine forming in sand forms, in cement forms, graphite and asbestos forms. It can be machine forming in shells, lost-wax casting, freeze mercury casting, centrifugal diecasting, gravity die-casting, pressure die-casting, gas casting, vacuum casting, electroslag casting, heat-insulation casting.

4. Vacuum molding is the technology of molding hot thermoplastic materials by vacuum or low air pressure. Vacuum molding is one of the ways of drawing various materials: a sheet of plastic is placed under or above a matrix (the form), then it is heated to the specified temperature, then the heated plastic sheet takes the matrix form, when the vacuum begins to put them together. One of the benefits of this method is the fact that you can use materials of different thickness up to $60 \mathrm{~mm}$. And you can also make forms significant in diameter (up to 5 meters). It doesn't mean great expenses and spending of materials for vacuum molding. The basic materials can be acrylic, polystyrene, ABS-plastic, PVC, PET, monolithic polycarbonates, etc [5].

5. 3-D printing is a manufacturing process, built on layers, to create a three-dimensional solid object from a digital model. In 3D printing a lot of different materials are used.

6. Diamond drilling of the concrete is a process, when a diamond tool creates a cylindrical hole in concrete, reinforced concrete, brick, stone, and many other building materials. This technology is used in building for creating technical openings for laying different services, for creating niches in concrete and brick walls, for cutting openings in supporting walls and slabs or floors [5].

Originally, the application of perforating was limited by only technical requirements, as the metal was used for producing technological elements, such as sifting and filtering devices in agriculture, in food industry and in machinery. Later, the perforation gains a decorative and artistic significance; it becomes a conceptual element in design. Art objects, sculptures, exhibition spaces are created with the help of the perforation principle. At present, the range of functional application of perforated surfaces is quite wide. It is used in soundproofing, acoustics, sun screening, object and interior design, architectural design, 
building etc. Nowadays, flat surfaces with perforation are widely used and are highly appreciated among many other building materials that are available in building materials market.

The most prominent example of using perforated metal sheets on a large scale by designers has become a bowling club «Depo-2000» in Moscow in 1999. More than 300 square meters of perforated aluminum sheets were used for interior finishing [5]. This material has many unique qualities that are suitable for solving many interior problems. The using of perforated panels is not only connected with design but also with its functional features. For example, you can fix mounted elements, such as shelves, brackets etc.

Application of perforated sheets in order to increase the lighted surface of the wall makes such sheets of panels irreplaceable in creating public spaces. In commercial units the application of perforation creates portable conditions of devices for exhibiting goods according to compositional ideas of designers. Therefore, we can't imagine most part of trade equipment without perforated surfaces such as shelf stands panels in supermarkets and self-service shops, wall panels as supporting and decorative elements, shelves, information stands, that can be easily transformed to the needs of the exhibition, demonstrative and exhibition stands, lift holders for advertising etc.

Perforated surfaces in architecture can be used as façade elements, roof elements, soundproofing elements, wind and sun screening elements, window shields, balcony and stair fences. So, perforated elements are widely used for creating functional and artistic effects. Perforated surfaces are used in interior design as well.

They can create decorative interior elements, wall and ceiling panels; they can also create different light effects and can be used in ventilated and false ceilings, in decorating radiators etc. Perforated sheets are widely used in furniture producing. Many screens, bar counters and receptions, wardrobe doors, shelves, chairs, benches, trade equipment are made of perforated sheets.

Perforated surfaces have become more common in the environmental design and land management. Many small architectural forms, such as playgrounds, bus stops, benches, trash bins, lights, fences, signs, fountains, art-objects, sheds etc. are created with the help of perforated surfaces.

Apart from the artistic role, perforated surfaces play a functional role in architecture and design. So, the ventilated façade is impossible without perforation. The perforated facades have such benefits as achieving all architectural goals without losing functional and physical characteristics of exploiting facades in different seasons. It can remove aqueous condensation, cool the outer part of facades due to air circulation. It can also reduce the heat flow during summer months and prevent the heat loss in winter months. Mainly, they're long lasting materials, that won't need repairing within 40-50 years and they provide the soundproofing of the building.

Architects and designers got an opportunity to design buildings, using perforation on wooden and concrete large panels. This has become available due to the modern technologies. The application of perforated surfaces has allowed not only changing the outer appearance of the object, but also completely changing the feeling of the forms and spaces of the object. The quality of interacting with natural and artificial light is actively used, because it changes the appearance of the building in different times of the day.

The perforation principle is widely used in other spheres of modern design. For example, it is used in fashion design and costume design. The laser cutting technology plays a crucial role in getting holes in fabrics, leather and faux leather. Laser burns out the holes, so the edges of materials are melted. That lets us not process fabrics with an overlock machine. It minimizes the thermal impact on fabrics and gives the best results in short terms [6]. 


\section{Experiment}

The analysis has shown that art perforation can play the main role in an architect's and a designer's scenario, as it gives really unique features to an object, and it can be used both in small and large objects. Here are the examples:

The Museum building in Palmyra (Poland). Architects: WXCA. Part of the exposition is surrounded with walls with holes in them that symbolize bullets. Each hole in the museum's "skin" stands for a Polish citizen who was killed during the Holocaust. The appearance of the building brings up a lot of emotions, while the perforation plays the major role in creating these emotions. It reminds people of the cruelty that reigned during WW II [7].

The Pharmacy in Athens (Greece). Architects: Bureau of architecture "Club Architecture". Façade panels are covered with perforation that shows Braille alphabet. This calls the attention of the audience to the problems of the blind who should be socially integrated. Apart from the artistic meaning, the perforation provides the building with the panoramic glazing of the first floor. At noon the interior of the building is filled with sunlight.

The kindergarten building in Valencia (Spain). Architects: Studio P. The wall perforation is a decorative element, that makes the building and concrete look more lively, it also creates an available environment and a gaming atmosphere, it improves the visual communication as well [8].

The School in Girona (Spain). Architects: Javier de las Eras and Bosh Tarrus. The structure of the building is modeled in a special way to protect the windows with multifunctional perforated metal sheets that simultaneously play the role of a sun screen and a fence of the playground. A stylish decoration of window openings prevents from peeping into the building and from interrupting functional processes in the school building.

The installation by Stephen Hall "From porosity to alloys" (an «Entrez lentement» exhibition organized by Pierre Luigi Nicolin and dedicated to Mayer's villa by the architect Alvara Alto) is a series of wrongly shaped figures with perforated surfaces. The perforation creates different shapes that interact with luminous fluxes [9].

A game of light and shadow deforms objects, it creates optical and light effects, it makes a new formation, divides forms into pieces. It artistically changes objects. The main ways of interactions of a luminous flux with a perforated plane (with different shapes and pictures, created during the research) and three-dimensions were tested during the experimental design and modeling in a student's workshop of "The Environmental design" in the Academy of building and Architecture (Samara, Russia). The patterns of formation in architectural compositions were studied in the following nominations: 1) the interaction of perforation, a luminous flux and a plane; 2) the interaction of perforation, a luminous flux and lapidarus volume; 3 ) the interaction of perforation, a luminous flux and a group of objects; 4) the interaction of perforation, a luminous flux and complicated in shape objects.

\section{Results}

The results of experimental modeling formed the basis of designing architectural installations, which can become a prototype for art objects, small objects, pavilions, public buildings. An architect or a designer get a completely new tool for object formation in the city environment by changing the shape of perforation, its scale, by using rhythmical and metrical codes, by changing angles of interactions with luminous fluxes. All these techniques give an opportunity to endlessly transform artistic appearances. 

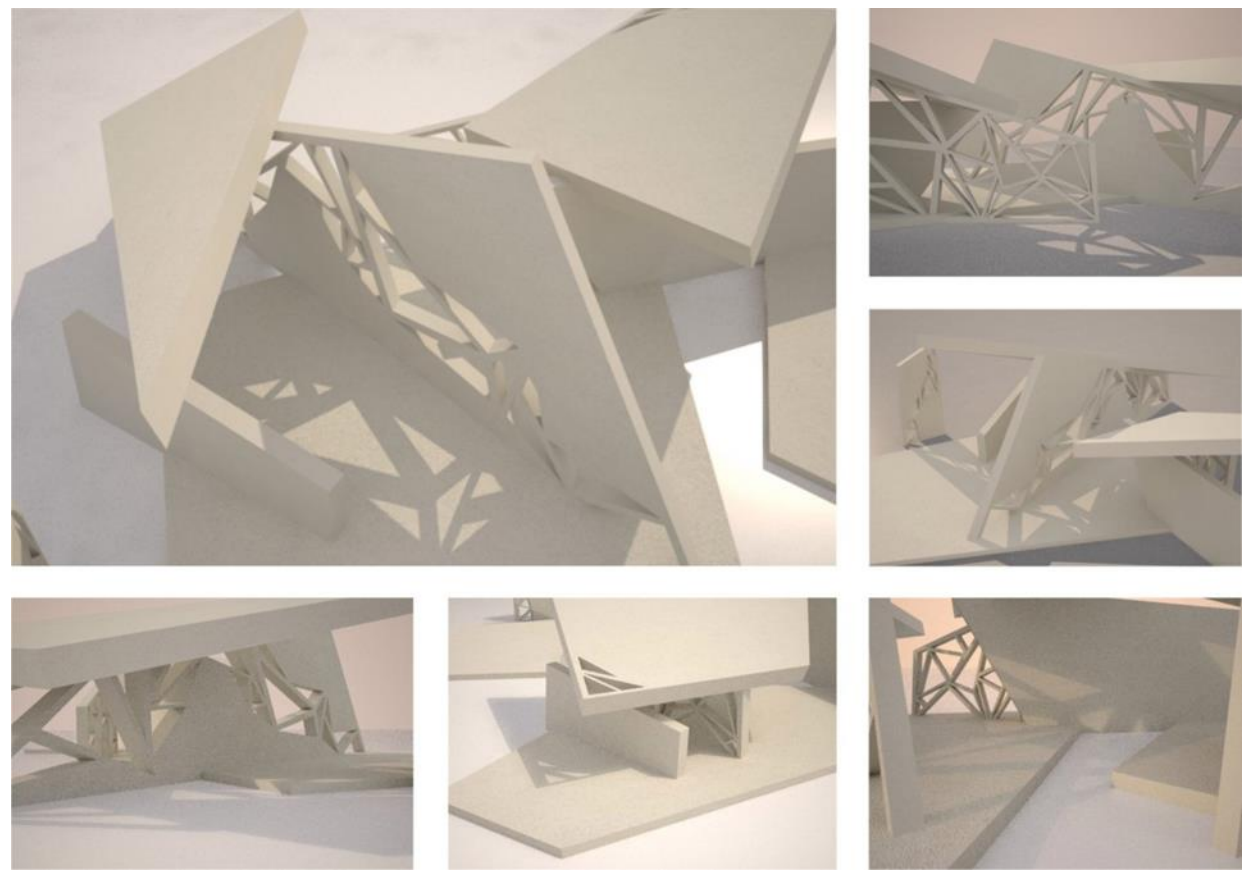

Fig. 1. The experimental three-dimensional model with perforated planes application.

The perforation of plane and 3D surfaces does not only interfere with the functions of the objects, it also becomes a decorative element and a powerful tool for searching new formations and new spatial effects.

\section{Conclusion}

At the current stage of the development of architecture and design, perforated surfaces are up-to-date materials with both decorative and technical functions. They have a wide range of applications. Different 3D compositions of perforated materials are distinguished by their lightness, artistic filigree perforation that creates the game of light. Therefore, it can be said that the perforation principle is a versatile and multipurpose tool that can be applied to different materials and provide us with a wide scope of artistic effects in modern designing. An architect and a designer can experience a new effect called irradiance. It is the effect when perforation changes its geometrical features and creates new different form illusions under the luminous flux. Surfaces that are perforated with an ornament go beyond the traditional using of ornaments in environmental design and architecture in their aesthetics. The harmonization of technical and productive processes and the broadening of mass culture horizons bring the demand for unique and individual solutions. The artistic perforation can meet such demands. And unlike the décor function, perforation becomes a full member of a spatial 3D design and composition design.

\section{References}

1. I.A. Dobritsyna, The art of city planning 1, 464-470 (2006)

2. T.V. Karakova, City planning and architecture 1, 41-44 (2011)

3. V.E. Mikhailenko, Applied geometry and engineering drawings 22, 6-11 (1976) 
4. V.V. Ovchinnikov, The equipment, technics and the technology of welding and cutting metals (KnoRus, Moscow, 2010)

5. V.V. Ovchinnikov, Basic theory of welding and cutting metals (KnoRus, Moscow, 2011)

6. T.V. Karakova, U.O. Sidorova, City planning and architecture 2(10), 17-21 (2013)

7. I.A. Dobritsyna, From postmodernism to non-linear architecture, Architecture in the context of modern philosophy and science (Progress-Tradition, Moscow, 2004)

8. U.T. Bozhko, Architectonics and combinatorics of formation (High Sch., Kiev, 1991)

9. S. Holl, Idea. Phenomenon and Material (The Monacelli Press, New York, 2003) 